九州大学学術情報リポジトリ

Kyushu University Institutional Repository

\title{
Ultrastructural observations on the Sperm of two Apodemus species, Apodemus agrarius coreae and Apodemus speciosus peninsulae, in Korea
}

Lee, Jung-Hun

College of Natural Sciences, Kyungnam University, Korea

Mori, Takayuki

Faculty of Agriculture, Kyushu University

https://doi.org/10.5109/4722

出版情報：九州大学大学院農学研究院紀要. 51 (1)，pp. 125-133，2006-02-01. Faculty of Agriculture, Kyushu University

バージョン：

権利関係 : 


\title{
Ultrastructural observations on the sperm of two Apodemus species, Apodemus agrarius coreae and Apodemus speciosus peninsulae, in Korea
}

\author{
Jung-Hun LEE ${ }^{1 *}$ and Takayuki MŌRI \\ Laboratory of Zoology, Division of Zoology and Entomology, Department of Applied Genetics and \\ Pest Management, Faculty of Agriculture, Kyushu University, Fukuoka 812, Japan \\ (Received October 30, 2005 and accepted November 16, 2005)
}

\begin{abstract}
Sperm morphology of Apodemus agrarius coreae, Apodemus speciosus peninsulae, laboratory mouse and rat were studied. The total length of the sperm of $A$. a. coreae, A. s. peninsulae, the mouse and rat was about $133 \mu \mathrm{m}, 124 \mu \mathrm{m}, 131 \mu \mathrm{m}$ and $192 \mu \mathrm{m}$, respectively. Two Apodemus sperm heads had a fish hook shape, while the mouse sperm head had a hook shape; thus, the sperm heads of genus Apodemus were somewhat like those of the mouse. The rat sperm head was unlike the other species in that it had a falciform shape. In addition, two Apodemus spermatozoa had two well-developed ventral spurs (Vs), and the mouse sperm head also had two similar small Vs, but rat sperm head had low ridge line-like Vs. All species had a separated head-cap segment in the ventral side of the anterior acrosomal portion of sperm. In the neck region, the vault formerly occupied by the proximal centriole was retained in a niche in the dense substance of the connecting piece in the spermatozoa of two Apodemus species, the mouse and the rat. The neck region of two Apodemus spermatozoa was surrounded by the scroll of a redundant nuclear envelope and a few large mitochondoria. In contrast, in the mouse and rat spermatozoa, the neck region was devoid of mitochondoria, except a fold of the redundant nuclear envelope. Since a very similar sperm head morphology occurs in the two Apodemus species and the mouse, it suggests that these genera are sister groups, to the exclusion of the rat.
\end{abstract}

Key Words: acrosome, Apodemus, sperm morphology, separated head-cap segment, spermatozoa, ventral spur.

\section{INTRODUCTION}

The subfamily Murinae contains more than 400 species of rats and mice, mainly in tropical Africa, Asia and Australia. Only two genera, Apodemus and Micromys, are predominantly Palaearctic, but the representatives of two others, Mus and Rattus, have become global through their association with people (Corbet and Harris, 1991). Except for an excellent and extensive report describing the sperm morphology of the mice and rats using the light microscope by Friend (1936) and sperm morphological feature of Apodemus sylvaticus by Moore et al. (2002), ultrastructural observations of the spermatozoa of two species - Apodemus a. coreae and $A$. s. peninsulae - are not known.

The aim of the present study was to investigate in detail the particular ultrastructure of the sperm of two Apodemus species, and to make a comparison with those of the laboratory mouse and the laboratory rat belonging muroid rodent.

\section{MATERIALS AND METHODS}

Adult specimens of the striped field mouse $A$. agarius coreae, Korean field mouse A. speciosus peninsulae, the mouse (ddY strain) and rat (Wistar strain) were used in the present study. Specimens were

${ }^{1}$ Division of Life Sciences, College of Natural Sciences, Kyungnam University, Kyungnam 631-701, Korea

* Corresponding author (E-mail: jhlee@kyungnam.ac.kr) killed by asphyxiation and the epididymides removed. For light microscopy, spermatozoa of two Apodemus species, mouse and rat were flushed from the cauda epididymis, were smeared on slide glasses at room temperature for $5 \mathrm{~min}$., and washed in $0.1 \mathrm{M}$ Milloing's buffer (pH 7.4). They were then fixed in $3 \%$ glutaraldehyde (0.1 M Milloing's buffer, $\mathrm{pH} 7.4$ ) and dehydrated in a graded series of ethanol for $10 \mathrm{~min}$, respectively. These samples were observed without staining under the light microscopy.

In scanning electron microscopy, the samples smeared on slide glasses were fixed and dehydrated as light microscopic methods, and coated with gold, and observed under Akashi SX-40 scanning electron microscope at $15 \mathrm{kV}$. For transmission electron microscopy, after following fixation in $3 \%$ glutaraldehyde in $0.1 \mathrm{M}$ Milloing's buffer ( $\mathrm{pH} 7.4$ ) for $4 \mathrm{hr}$, the tissues were washed in the same buffer, postfixed in $1.3 \%$ osmium tetroxide in the same buffer for $2 \mathrm{hr}$, and dehydrated in a graded series of ethanol and embedded in Epoxy resin. Thin sections $(60-90 \mathrm{~nm})$ were stained with uranyl acetate and lead citrate, and examined with an $\mathrm{H}-600$ (Hitachi) transmission electron microscope at $75 \mathrm{kV}$.

\section{RESULTS}

The sperm morphology of Apodemus agrarius coreae, Apodemus speciosus peninsulae, mouse and rat were described (Figs 1-17, Text-fig. 1), and the dimensions of the spermatozoa were summarized in Table 1. 
Table 1. Comparison of the sperm morphology of Apodemus agrarius coreae, Apodemus speciosus peninsulae, mouse and rat

\begin{tabular}{|c|c|c|c|c|c|c|c|c|c|}
\hline \multirow{2}{*}{ Species } & \multicolumn{4}{|c|}{ Head $(\mu \mathrm{m})$} & \multicolumn{4}{|c|}{ Tail $(\mu \mathrm{m})$} & \multirow{2}{*}{$\begin{array}{l}\text { Total length of } \\
\text { the sperm }\end{array}$} \\
\hline & $\mathrm{L}$ & W & $\mathrm{Nul}$ & $\mathrm{S}$ & $\mathrm{Tl}$ & $\mathrm{Nl}$ & Mp & $\mathrm{Pp}+\mathrm{Ep}$ & \\
\hline Apodemus agrarius corea & 8.0 & 4.0 & 7.6 & $\mathrm{FH}$ & 125.5 & $0.8-1.0$ & 29.5 & 95.0 & 133.3 \\
\hline A. speciosus peninsulae & 7.8 & 3.6 & 7.6 & $\mathrm{FH}$ & 116.3 & $0.8-1.0$ & 22.5 & 93.0 & 124.1 \\
\hline Mouse (ddY strain) & 7.3 & 3.4 & 6.6 & $\mathrm{H}$ & 124.2 & $0.8-1.0$ & 23.5 & 99.5 & 131.5 \\
\hline Rat (Wistar strain) & 12.0 & 1.6 & 10.6 & $\mathrm{~F}$ & 180.0 & $0.8-1.0$ & 63.0 & 116.2 & 192.0 \\
\hline
\end{tabular}

F, falciform; FH, fish hook; $\mathrm{H}$, hook; L, length; Mp, middle piece; Nl, neck length; Nul, nuclear length; Pp + Ep, principal piece plus end piece; $\mathrm{S}$, sperm head shape; Tl, tail length; $\mathrm{W}$, width.

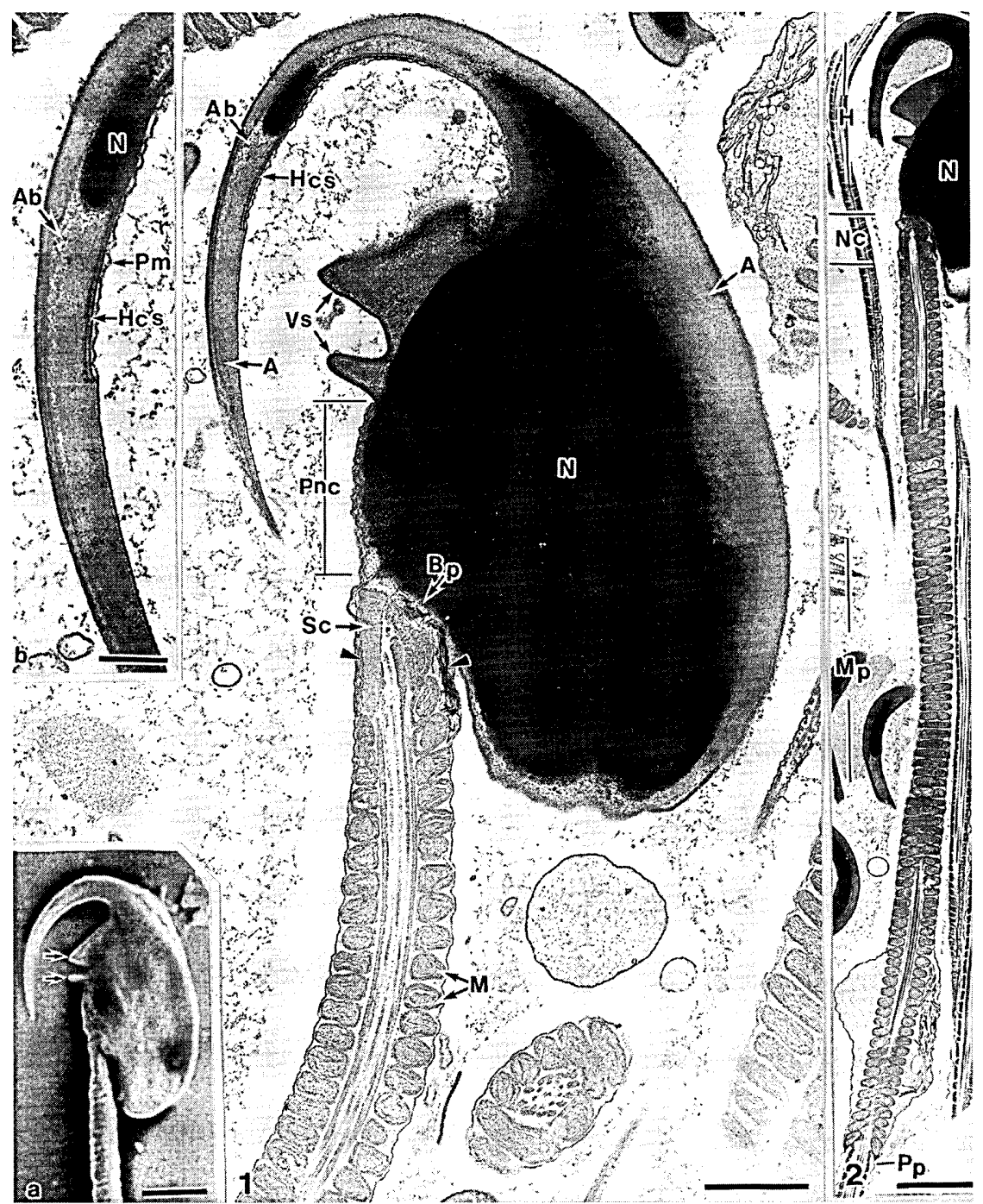

Fig. 1. Transmission and scanning electron micrographs showing the caudal epididymal spermatozoa of Apodemus agrarius coreae. Sperm head had a sharply curved fish hook shape, and acrosome (A) covering the apical body (Ab) is seen. The sperm head has two ventral spurs (Vs) on the ventral region of sperm head with an opener-like form (Fig. 1, arrows in Fig. 1a), and the separated head-cap segment (Hcs) is clearly visible (Fig. 1, 1b). The post-nuclear cap (Pnc) occupied about a third of nucleus. The basal plate (Bp) was adherent to the nuclear envelope, defining the implantation fossa. The segmented columns (Sc) were surrounded by redundant membranous scroll (arrowheads in Fig. 1), and adjacent outer membrane of the first mitochondria of the middle piece. The proximal centriole had degenerated. M, mitochondria; Pm, plasma membrane. N, nucleus. Scale bars $=1 \mu \mathrm{m}$ (Fig. 1), $2 \mu \mathrm{m}$ (inset a), $0.2 \mu \mathrm{m}=$ (inset b).

Fig. 2. Longitudinal section of the middle piece of in A. agrarius coreae. Mitochondrial gyres were 188 approximately. H, head; Mp, middle piece; N, nucleus; Nc, neck; Pp, principal piece. Scale bar $=2 \mu \mathrm{m}$. 


\section{Apodemus agrarius coreae}

Sperm head

The shape of the sperm head of $A$. a. coreae had a sharply curved fish hook (Fig. 1, inset a in Fig. 1). The sperm head was $8.0 \mu \mathrm{m}$ in length, whose posterior $7.6 \mu \mathrm{m}$ was occupied by a nucleus, being about $4.0 \mu \mathrm{m}$ in width (Table 1). The spermatozoon had two well-developed ventral spurs (Vs) with an opener-like form on the ventral region of the sperm head (Fig. 1, inset a in Fig. 1, Fig. 2). The acrosome covered about two-thirds of the anterior portion of the sperm head. The apical body outlined by the inner acrosomal membrane extended to the tip of the very long subacrosomal space as an finger like projection (Fig. 1, inset b in Fig. 1). The sperm head of this species was characterized by the presence of a separated head-cap segment (Hcs) on the ventral side of anterior acosomal portion of sperm nucleus (Fig. 1, inset b in Fig. 1). The post-nuclear cap (Pnc) occupied about a third of nucleus (Fig. 1, Text-figs 1, 2). The equatorial segment of acrosome was situated on the middle portion of the nucleus (Text-figs 1, 2).

\section{Sperm tail}

The total length of the sperm tail of $A$. a. coreae was $125.3 \mu \mathrm{m}$ with a long middle piece. The sperm tail consisted of four segments: the neck $(0.8-1.0 \mu \mathrm{m})$, middle piece $(29.5 \mu \mathrm{m})$, and principal piece plus end piece (95.0 $\mu \mathrm{m})$ (Fig. 2).

The neck region consisted of the basal plate, the capitulum, the persistence of the poximal centriole, traces of the distal centriole and a few mitochondria (Figs 1, 6).

The basal plate adhering to the nuclear envelope, defining the implantation fossa, was a band of electron dense materials. The segmented columns were surrounded by redundant membranous scroll of nuclear envelope that extendeds into the neck region (Fig. 6), were adjacent to one or two longitudinary oriented mitochondria that project forward from the mitochondrial sheath of the middle piece (Fig. 6).

Major segmented columns were seen in the neck (Fig. 7a). Nos. 1, 5, 6 and 9 of the outer dense fibers were larger than the others (Fig. 7b). The total number of mitochondrial gyres of $A$. a. coreae was 188 . A fibrous sheath (Fs) and longitudinal column (Lc) of the principal piece were in evidence (Fig. 7c, d), but the fibrous sheath was not seen at the end piece (Fig. 7e).

The end of the middle piece was marked by the annulus, a thin dense ring to which the flagellar membrane is firmly adhered.

\section{Apodemus speciosus peninsulae \\ Sperm head}

The sperm head of the $A$. s. peninsulae had a sharply curved fish hook shape, and was slimmer than that of $A$. a. coreae (Fig. 8, cf. Fig. 1, Text-figs 1, 2). The sperm head of $A$. s. peninsulae was $7.8 \mu \mathrm{m}$ in length, whose posterior $7.6 \mu \mathrm{m}$ was occupied by a nucleus, being about $3.6 \mu \mathrm{m}$ in width (Table 1). A. s. peninsulae spermatozoon were two well-developed ventral spurs with an opener-like form on the ventral region of sperm head (Fig. 8, inset a in Fig. 8), as $A$. $a$. coreae (Fig. 1, inset a in Fig. 1). A separated head-cap segment existed on the ventral side of anterior acorosomal portion of sperm nucleus such as $A$. $a$. coreae. The post-nuclear cap occupied about a third of nucleus.

\section{Sperm tail}

The length of the sperm tail of $A$. s. peninsulae was $116.3 \mu \mathrm{m}$, and the sperm tail consisted of four major segments: the neck $(0.8-1.0 \mu \mathrm{m})$, middle piece $(22.5 \mu \mathrm{m})$, and principal piece plus end piece $(93.0 \mu \mathrm{m})$. The total number of mitochondrial gyres of $A$. s. peninsulae was 184.

The basal plate was adhered to the nuclear envelope, defining the implantation fossa, and consisted of a band of electron dense materials (Figs 8, 10). The segmented columns were surrounded by redundant membranous scroll of nuclear envelope, adjacent to one or two mitochondria that project forward from the mitochondrial sheath of the middle piece (Figs 8, 10, and 11a). The persistence of the proximal centriole and traces of the distal centriole were observed (Fig. 10).

The shape and number of the outer dense fibers were same as in A. a. coreae (Fig. 11b, c). The end of
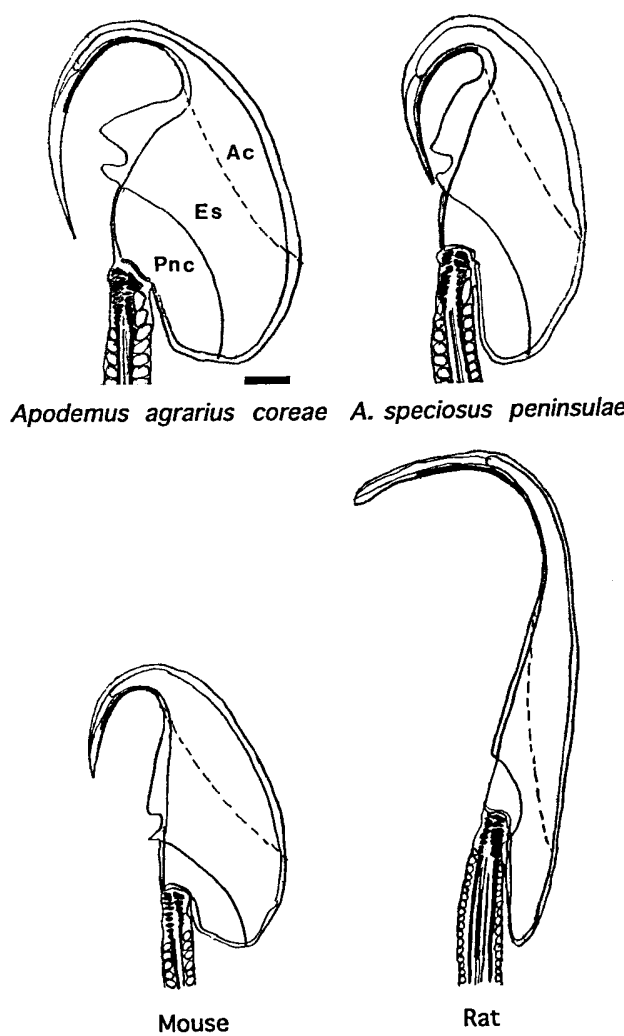

Text-fig. 1. Comparison of two Apodemus, mouse and rat sperm head. Two Apodemus species and mouse are very similar in the shape of the sperm head, but rat was different to the others. a, Apodemus agrarius coreae; b, Apodemus speciosus peninsulae; c, mouse; d, rat. Ac, acrosomal cap; Es, equatorial segment; Pnc, post-nuclear cap. Scale bar $=1 \mu \mathrm{m}$. 

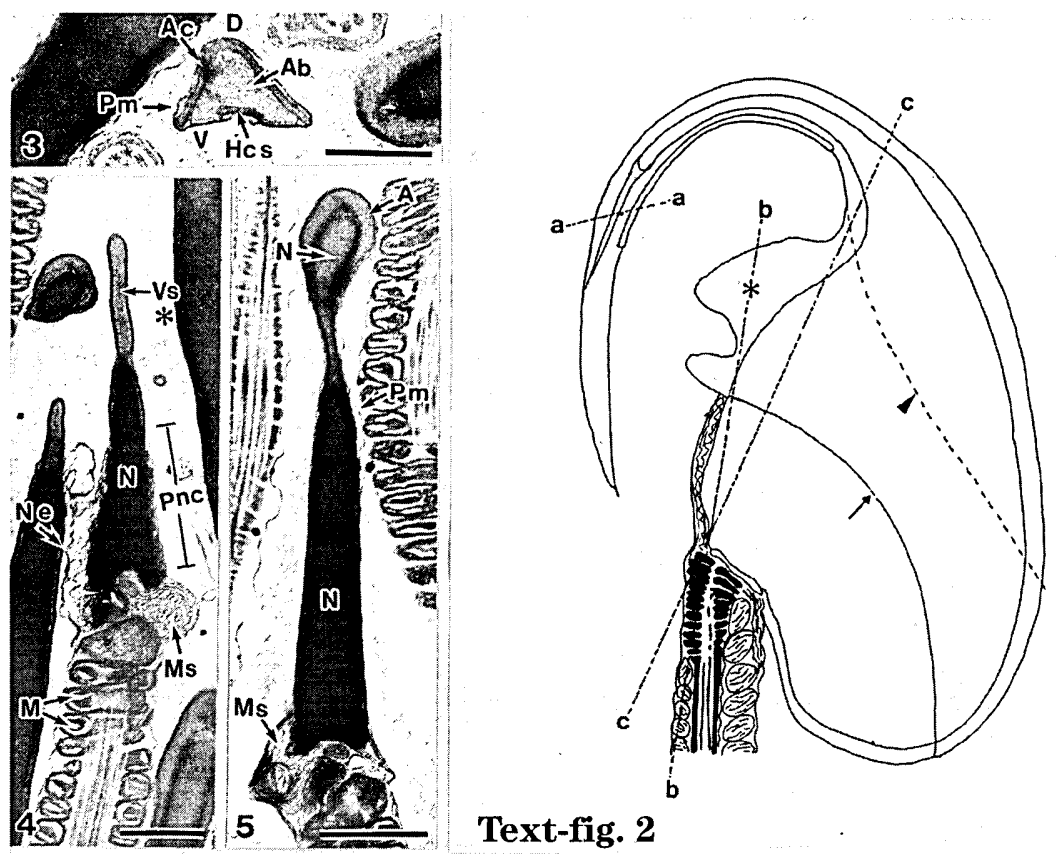

Text-fig. 2

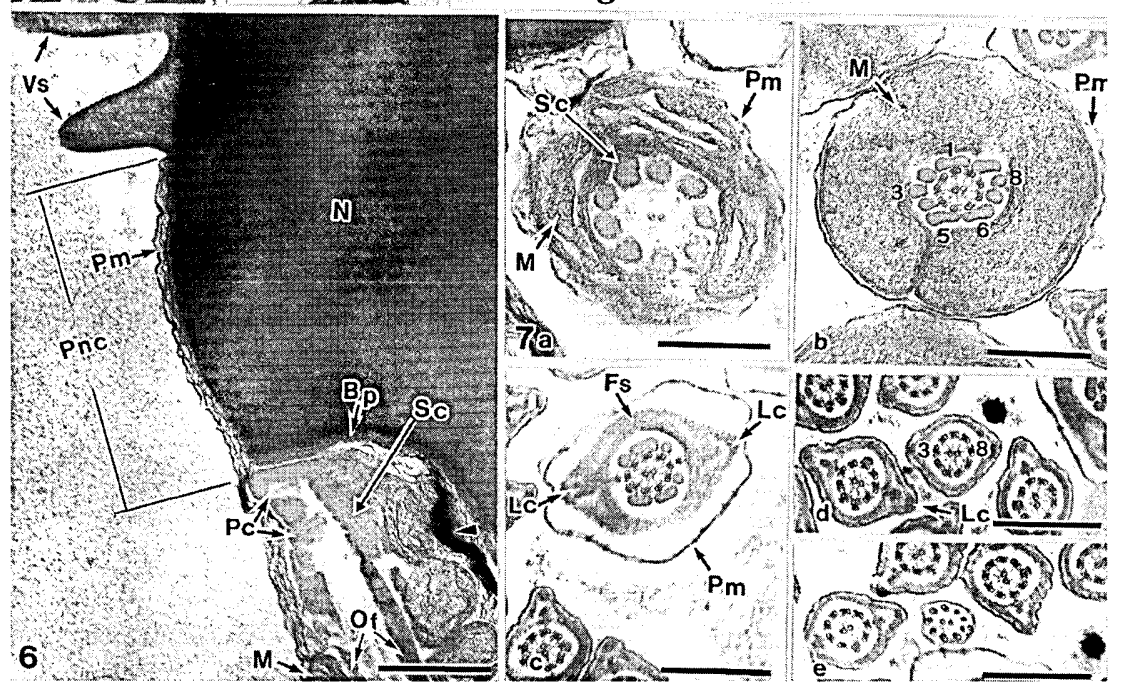

Text-fig. 2. Diagrammatic representation, based on scanning and transmission electron microscopy, of horizontal sections (such as Fig. 1) of the epididymal spermatozoon in A. agrarius coreae. a-a, Section passing through the separated head-cap segment (Hcs). b-b, Section passing through ventral spur (Vs) on the ventral region of sperm head. c-c, Section passing through the nucleus to ventral spur. A part of equatorial segment (Es) is located between the post-nuclear cap segment (arrow) and acrosomal cap (arrowhead) on the nuclear surface.

Fig. 3. Cross section through the anterior region of sperm head (cf. Text-fig. 2, a-a). The separated head-cap segment (Hcs) was seen in ventral region of sperm head. The apical body $(\mathrm{Ab})$ was covered by acrosomal cap (Ac). D, dorsal part; $\mathrm{V}$, ventral part; $\mathrm{P}$, plasma membrane. Scale bar $=0.5 \mu \mathrm{m}$.

Fig. 4. Sagittal section through the ventral spur (Vs) of sperm head in A. agrarius coreae (cf. Text-fig. 2, b-b). Note the ventral spur is a part of post-nuclear cap (Pnc). An acrosome (A) covers the anterior portion of the sperm head. M, mitochondria; Ms, membranous scroll; N, nucleus; Ne, nuclear envelope; Pm, plasma membrane. Scale bar $=1 \mu \mathrm{m}$.

Fig. 5. Parasagittal section of sperm head in A. agrarius coreae (cf. Text-fig. 2, c-c). The nucleus (N) was surrounded by the acrosome (A). A part of ventral spur (Vs) are seen. Ms, membranous scroll; N, nucleus; Pm, plasma membrane. Scale bar $=1 \mu \mathrm{m}$.

Fig. 6. Horizontal section of neck of A. agrarius coreae. The proximal centriole (Pc) was degenerated. Two ventral spur (Vs) and post-nuclear cap (Pnc) are clearly visible. The mitochondria were presented between segmented column and redundant membrous scoll (Ms). Bp, basal plate; M, mitochondria; Pm, plasma membrane; Se, segmented column. $\mathbf{\Delta}$, membranous scroll. Scale bar $=$ $0.5 \mu \mathrm{m}$.

Fig. 7a-e. Cross sections of the sperm tail in A. agrarius coreae. (a) Cross section of neck region. Segmented columns (Sc) and mitochondria (M) were seen. (b) Cross section of middle piece. Nos. 1, 5, 6 and 9 of the outer dense fibers were larger than the others. (c-e) Cross section of principal piece and end piece. The fibrous sheath (Fs) and longitudinal column (Lc) in the principal piece were seen, but fibrous sheath (Fs) was not seen at the end piece (fig. 7e). M, mitochondria; Pm, plasma membrane; Sc, segmented column. All scale bars $=0.5 \mu \mathrm{m}$. 


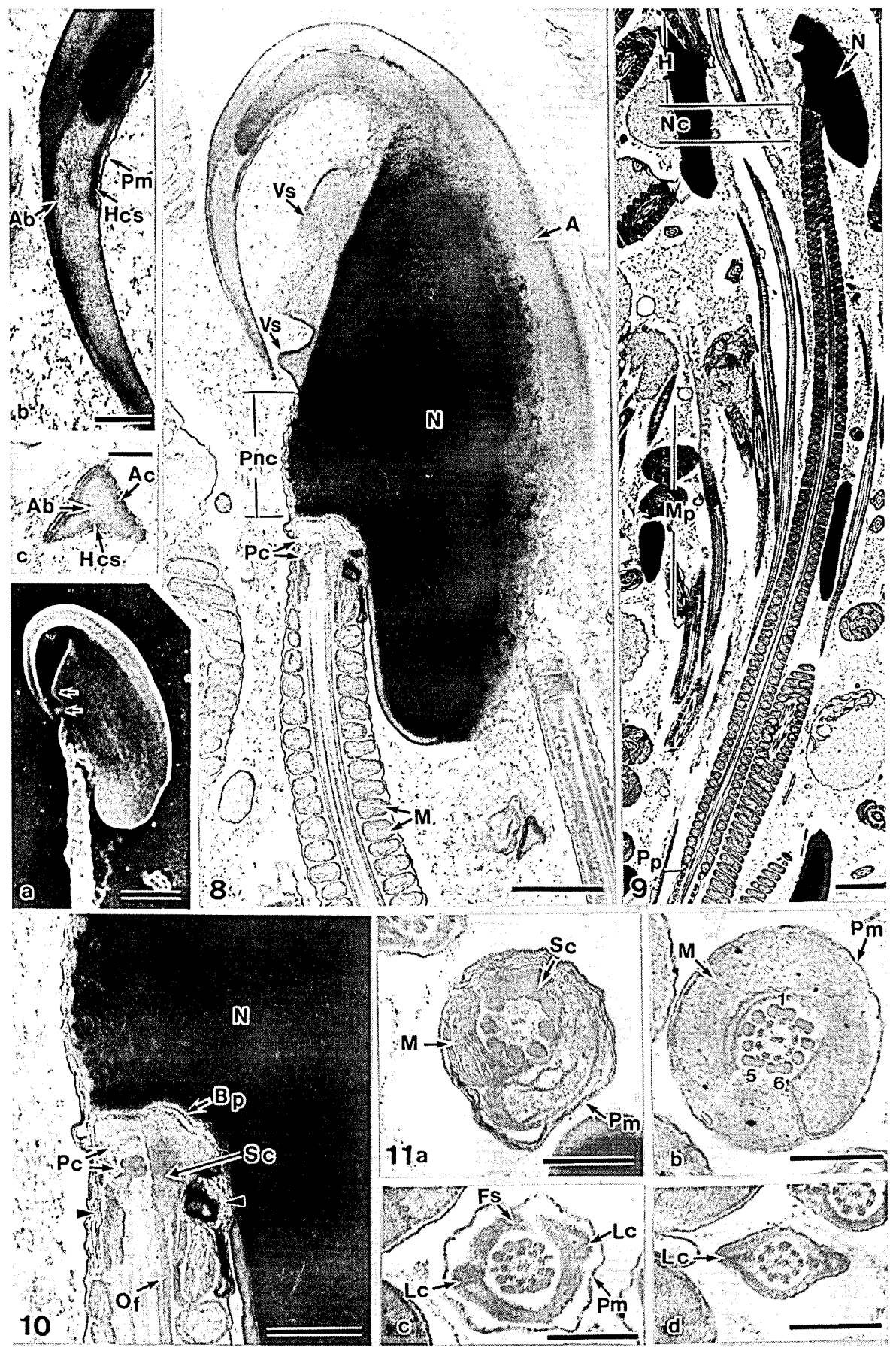

Fig. 8. Transmission and scanning electron micrographs showing the caudal epididymal sperm of $A$. speciosus peninsulae. Sperm head had a sharply curved fishhook shape, and acrosome (A) covering the apical body (Ab) was seen. Two ventral spur (Vs) existed on the ventral region of sperm head with an opener-like form (Fig. 8, inset a) such as $A$. a. coreae. Note the separated head-cap segment (Hcs) in the acrosome (inset $\mathrm{b}$ and $\mathrm{c}$ in Fig. 8) and mitochondria in neck region. Scale bars $=1 \mu \mathrm{m}$ (Fig. 8 ), $2 \mu \mathrm{m}$ (inset a), $0.2 \mu \mathrm{m}$ (inset $b, c)$.

Fig. 9. Longitudinal section of the middle piece of $A$. speciosus peninsulae. Mitochondrial gyres were 184 approximately. $\mathrm{H}, \mathrm{head} ; \mathrm{Mp}$, middle piece; $\mathrm{N}$, nucleus; Nc, neck; Pp, principal piece. Scale bar $=2 \mu \mathrm{m}$.

Fig. 10. Horizontal section of the neck of A. speciosus peninsulae. The proximal centriole (Pc) was degenerated. The basal plate (Bp) was adherent to the nuclear envelope, defining the implantation fossa. The segmented columns (Sc) are surrounded by redundant membrous scroll (arrowheads). Developed mitochondria were seen in the neck region. M, mitochondria; Pm, plasma membrane. Scale bar $=0.5 \mu \mathrm{m}$.

Fig 11a-d. Cross sections of the sperm tail in A. speciosus peninsulae. (a) Cross section of neck region. Segmented columns (Sc) were seen in neck region. (b) Cross section of middle piece. Nos. 1, 5,6 and 9 of the outer dense fibers were larger than the others. (c-d) Cross section of principal piece. The fibrous sheath (Fs) and longitudinal column (Lc) in the principal piece are seen. M, mitochondria; Pm, plasma membrane. Sc, segmented column. All Scale bars $=0.5 \mu \mathrm{m}$. 
the middle piece was marked by an annulus (Fig. 9), a thin dense ring to which the flagellar membrane firmly adhered (Fig. 11c, d).

\section{Mouse}

Sperm head

The shape of the sperm head of the mouse had a hook shape (Fig. 12). The sperm head was $7.3 \mu \mathrm{m}$ in length, with a posterior $6.6 \mu \mathrm{m}$ occupied by a nucleus, being about $3.4 \mu \mathrm{m}$ in width (Table 1). The mouse sperm head had two ventral spurs with an opener-like form on the ventral region of the sperm head, as in the two Apodemus sperm (Text-fig. 1). Mouse sperm had the separated head-cap segment on the ventral side of the anterior acrosomal portion of the sperm nucleus (inset in Fig. 12), as in the two Apodemus sperm (cf. Fig. 3, Fig. 8b, c). In the post-nuclear cap, the mouse sperm occupied about a quarter of the nucleus.

\section{Sperm tail}

The length of the sperm tail of the mouse was $124.2 \mu \mathrm{m}$, and the sperm tail consisted of four major seg- ments: the neck $(0.8-1.0 \mu \mathrm{m})$, middle piece $(23.5 \mu \mathrm{m})$, and principal piece plus end piece $(99.5 \mu \mathrm{m})$.

The segmented columns were surrounded by redundant, membranous scroll of nuclear envelope (Fig. 13). The proximal centriole had degenerated (Fig. 13), as in the two Apodemus species.

Segmented columns were seen in the neck (Figs 12, 13). The cross section of the middle piece showed a singular arrangement of the outer dense fibers, with similar numbers and central tubules. Nos. 1, 5, and 6 of the outer dense fibers were distinctly larger than the others (Fig. 14b). In the principal piece, a fibrous sheath and longitudinal column were obserbed in evidence (Fig. 14c).

\section{Rat}

Sperm head

The shape of the sperm head of the rat had a slender falciform (Fig. 15). The sperm head was $12.0 \mu \mathrm{m}$ in length, with a posterior $10.6 \mu \mathrm{m}$ occupied by a nucleus of about $1.6 \mu \mathrm{m}$ width (Table 1). Rat spermatozoa had one ventral spur on the ventral region of the

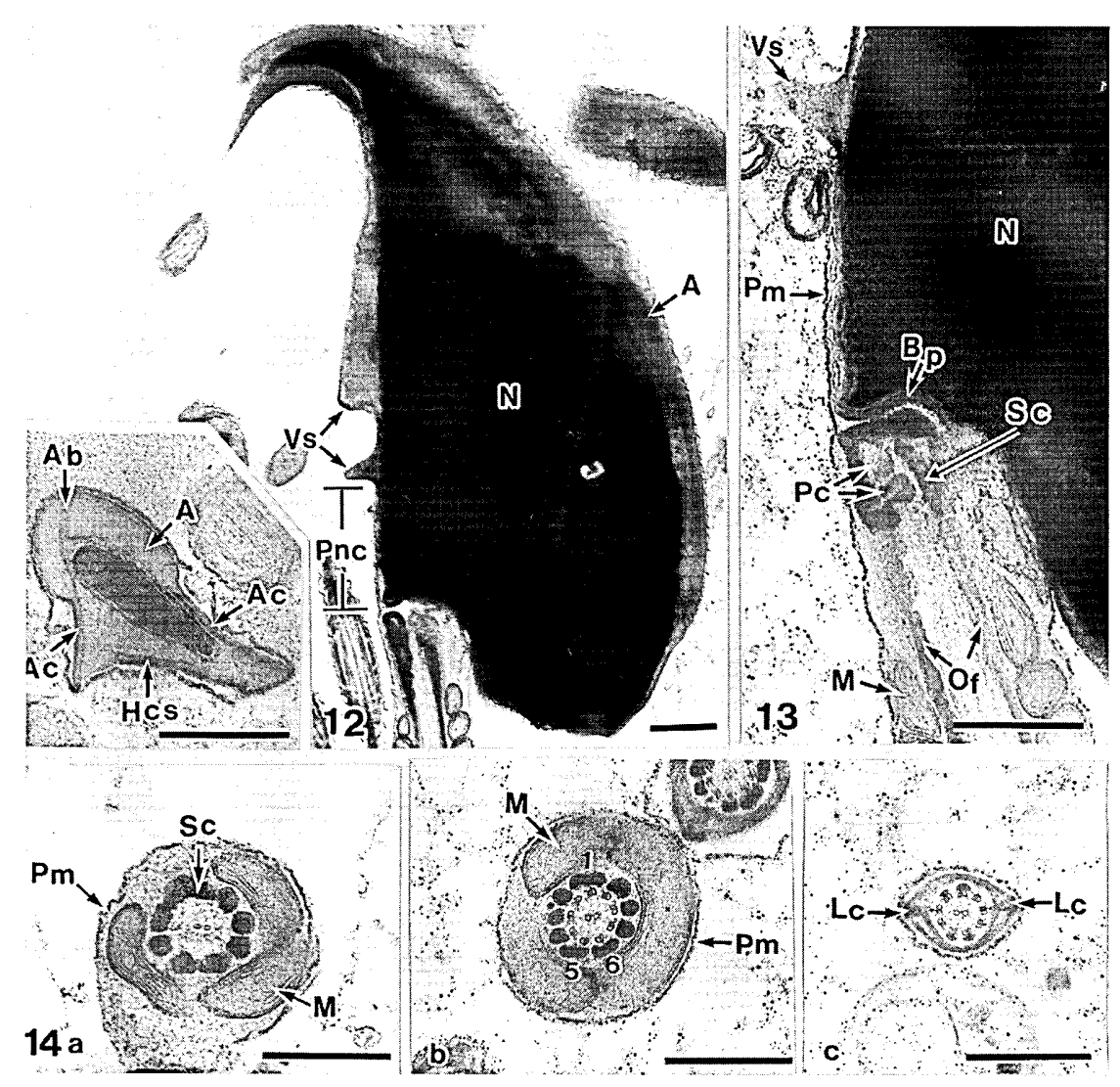

Fig. 12. Transmission electron micrographs showing the caudal epididymal spermatozoa of mouse. Sperm head had a curved hook shape, and acrosome (A) covering the apical body ( $\mathrm{Ab}$ ) is seen. Note two ventral spurs (Vs) on the ventral region of the sperm head. The separated head-cap segment (Hcs) was clearly visible (inset in Fig. 12). All Scale bars $=0.5 \mu \mathrm{m}$.

Fig. 13. Horizontal section of neck region in the mouse. Note the degenerated proximal centriole. Bp, basal plate; M, mitochondria; N, nucleus; Of, outer dense fiber; pm, plasma membrane; Pnc, post-nuclear cap; Se, segmented column. Scale bar $=0.5 \mu \mathrm{m}$.

Fig. 14a-c. Cross sections of the sperm tail in mouse. (a) Cross section of lower part of neck region. Major segmented columns (Sc) were seen. (b) Cross section of middle piece. Nos. 1,5 and 6 of the outer dense fibers were larger than the others. (c) Cross section of principal piece. The fibrous sheath (Fs) and longitudinal column (Lc) are seen (Fig. 14c). M, mitochondria; Pm, plasma membrane. All scale bars $=0.5 \mu \mathrm{m}$. 
sperm head (Fig. 15). The head had a separated head-cap segment on the ventral side of the acrosome of the anterior acrosomal portion of sperm nucleus, as in the two Apodemus species and mouse sperm (inset $\mathrm{b}$ in Fig. 1, inset b and inset $\mathrm{c}$ in Fig. 8, inset in Fig. 12). The post-nuclear cap of the rat occupied about a seventh of nucleus (Fig. 15, Text-fig. 1).

\section{Sperm tail}

The length of the sperm tail of the rat was $180.0 \mu \mathrm{m}$, and the sperm tail consisted of four major segments: the neck $(0.8-1.0 \mu \mathrm{m})$, middle piece $(63 \mu \mathrm{m})$, and principal piece plus end piece $(116.2 \mu \mathrm{m})$.

The segmented columns were surrounded by mem- branous scroll of nuclear envelope, adjacent to one or two mitochondria that project forward from the mitochondria sheath of the middle piece (Fig. 16). The persistence of the proximal centriole and traces of the distal centriole were observed.

Several major segmented columns are fused (Fig. 17a). Nos. 1, 5 and 6 fibers of the outer dense fibers were larger than the others. The mitochondria were small in size than those of the two Apodemus and mouse sperm (cf. Figs 7a, 11b and 14b). There were numerous satellite fibers around the adaxial surfaces of the outer dense fibers in the middle piece (Fig. 17b). A fibrous sheath and longitudinal column of the principal piece were evident (Fig. 17c).

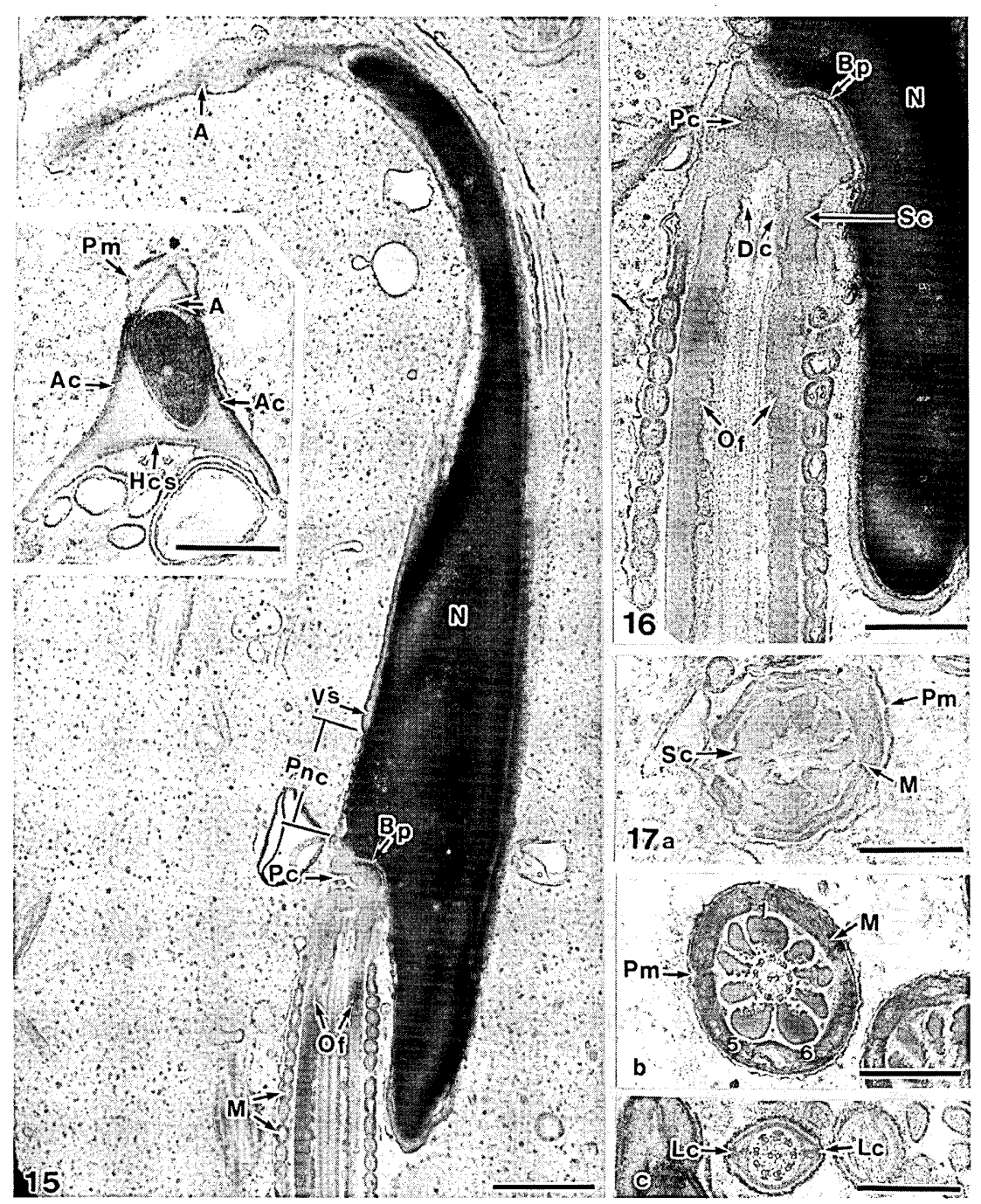

Fig. 15. Transmission electron micrographs showing the rat caudal epididymal spermatozoa. Sperm head had a falciform shape. Spermatozoon has only one small a loof-like ventral spur $(\mathrm{Vs})$ on the ventral region of sperm head. The separated head-cap segment (Hcs) existed in the ventral side of anterior portion of sperm nucleus. A, acrosome; Ac, acrosomal cap; Bp, basal lamina; M, mitochondria; N, nucleus; Of, outer denser fiber; Pm, plasma membrane. Scale bars $=1 \mu \mathrm{m}$. Fig. 15 inset, $0.5 \mu \mathrm{m}$.

Fig. 16. Horizontal section of neck region of the rat. Note the degenerated proximal centriole, the two major segmented columns (Sc) and anterior extension of the central pair of microtubules (Mt) through the distal centriole. B, basal plate; M, mitochondria; N, nucleus; Of, outer dense fiber. Scale bar $=0.5 \mu \mathrm{m}$.

Fig. 17a-c. Cross sections of the sperm tail in rat. (a) Cross section of neck region. Several segmented columns (Sc) were fused. (b) Cross section of middle piece. Nos. 1, 5 and 6 of the outer dense fibers were larger than the others, and the dimension of mitochondria was slander than two Apodemus species and mouse. Note the electron dense granules in the dense fiber cortex. (c) Cross section of principal piece. The fibrous sheath and longitudinal column (Lc) in the principal piece were seen. M, mitochondria; Pm, plasma membrane. All scale bars $=0.5 \mu \mathrm{m}$. 


\section{DISCUSSION}

In most mammalian species, the head shape is ovoid or spatulate, but in murid rodents there is usually an apical hook consisting of nuclear, subacrosomal and acrosomal material (Friend, 1936; Fawcett, 1970; Lalli and Clermont, 1981; Breed, 1983; Flaherty and Breed, 1983; Breed, 1984). In the sperm morphology and the ultrastructure of the striped field mouse Apodemus agrarius coreae and the Korean field mouse Apodemus speciosus peninsulae belonging to the subfamily Murinae, the sperm heads had a sharply curved fish hook shape, having two, well-developed ventral spurs (Vs) on the ventral region of sperm head. In Murinae, the two major subfamilies (Muridae and Cricetidae) have species with the same type spermatozoa, and the two families evolve separately, and within each family at least two separate evolutionary trends can be detected in Muridae, that is, the Rattus lineage and Hydromynae lineage (Roldan, et al., 1991).

The sperm morphology of the Australian hydromyine rodents is characterized by the presence of three curved hooks on the apical margin of the sperm head (Breed and Sarafis, 1979; Breed, 1980). In the plains mouse, Pseudomys australis, during Step13, spermatogenic step, the two ventral hooks elongate to full length (Flaherty and Breed, 1987), and the dorsal hook contains nuclear, acrosomal, and subacrosomal material, whereas the two ventral hooks appear to consist largely of an extension of the material in the subacrosomal space (Breed, 1983, 1984, Flaherty and Breed, 1983, Breed et al., 2000). In Apodemus spermatozoa, ultrastructural studies have revealed that the two ventral spurs contain subacrosomal material, in a fine structure similar to the two large ventral processes (hooks) of the plains mouse, Pseudomys australis (Flaherty, 1987).

The ventral spurs have been shown in the present study to consist of a continuation of the post-nuclear cap region. Although the postacrosomal region has been implicated as the initial site of sperm-egg fusion (Yanagimachi and Noda, 1970), recent studies suggest that this is primarily a function of the equatorial segment (Bedford et al., 1979; and Moore and Bedford, 1983). On the basis of their shape, inherent rigidity, and position, it has been postulated that the ventral spurs may function in assisting the mechanical penetration of the zona pellucida (Flaherty et al., 1983; Breed, 1984; Flaherty, 1987). The functional significance of the well-developed ventral spurs of Apodemus sperm remains unknown.

In the neck region of two Apodemus sperm, a degenerated proximal centriole occupied a niche in the dense substance of the connecting piece, as it does in the mouse and the rat. The neck region of two Apodemus spermatozoa is surrounded by a mass of redundant nuclear envelope and large mitochondoria that project forward from the mitochondorial sheath of the middle piece, but in the mouse and rat spermatozoa, the neck region is slender and devoid of mitochondoria except for a fold of redundant nuclear envelope.

The sperms of the genus Apodemus are similar to those of laboratory mouse, in having a sperm head with a curved hook and thus being mouse-like, although the detailed ultrastructure of their neck region on features of the redundant nuclear envelope and mitochondoria varies Apodemus and mouse. The rat is unlike the mouse and Apodemus spermatozoa in having a falciform shaped head as well as a very long tail with different ultrastructure.

From the viewpoint of taxonomic implications, since a very similar morphology occurs in the two Apodemus species and the mouse, it suggests that these genera are sister groups, to the exclusion of the rat.

\section{ACKNOWLEDGMENTS}

"This work was supported by the Korea Research Foundation Grant (KRF-2003-013-E00002). The authors are very grateful to Dr. I. Iida and T. Kaneko for support.

\section{REFERENCES}

Bedford, J. M., H. D. M. Moore, E. Franklin 1979 Significance of the equatorial segment of the spermatozoa in eutherian mammals. Exp. Cell Res. 119: 119-126

Breed, W. G. 1980 Further observations on spermatozoal morphology and male reproductive tract anatomy of Pseudomys and Notomys species (Mammalia: Rodentia). Trans. Roy. Soc. S. Aust. 104: 51-55

Breed, W. G. 1983 Variation in sperm morphology in the Austrian rodent genus, Pseudomys (Muridae). Cell Tissue Res., 229: $611-625$

Breed, W. G. 1984 Sperm head structure in the Hydromyinae (Rodentia: Muridae); a further evolutionary development of the subacrosomal space in mammals. Gamete Res., 10: $31-44$

Breed, W. G., D. Idriss, R. J. Oko 2000 Protein composition of ventral processes on the sperm head of Austrailian Hydromyine rodents. Biol. Reprod., 63: 629-634

Breed, W. G., V., Sarafis 1979 On the phylogenetic significance of the spermatozoal morphology and male reproductive tract anatomy in Australian rodents. Trans. Roy. Soc. S. Aust. 103: $127-135$

Corbet, G. B., S, Harris 1991 The handbook of British mammals. Blackwell Scientific Publications, Oxford London Edinburgh, pp 191-259

Fawcett, D. W. 1970 A comparative view of sperm ultrastructure. Biol. Reprod., (Suppl. 1): 90-127

Flaherty, S. P. 1987 Further ultrastructural observations on the sperm head of the plains mouse, Pseudomys austrailis (Rodentia: Muridae). Anat. Rec., 217: 240-249

Flaherty S. P., W. G. Breed 1983 The sperm head of the plains mouse, Pseudomy australis: ultrastructure and effects of chemical treatments. Gamete Res. 8: 231-244

Flaherty, S. P., W. G. Breed 1987 Formation of the ventral hooks on the sperm head of the plains mouse, Pseudomys australis. Gamete Res. 17: 115-129

Flaherty S. P., W. G. Breed, V. Sarafis 1983 Localization of actin in the sperm head of the plains mouse, Pseudomys australis. J. Exp. Zool. 225: 497-500

Friend, G. F. 1936 The sperms of the British Muridae. Q. J. Microsc. Sci., 78: 419-443

Lalli, M., Y. Clermont 1981 Structural changes of the head components of the rat spermatid during late spermiogenesis. Am J Anat 160: 419-434 
Moore, H., J. M. Bedford 1983 The interaction of mammalian gametes in the female. In "Mechanism and control of animal fertilization". ed by Hartmann J. F., Academic Press, New York, pp 454-497

Moore, H, Dvrakova K, Jenkins N., W. Breed 2002 Exceptional sperm cooperation in the wood mouse. Nature, 418: 174-177

Roldan, E. S. R., A. D., Vitullo, M. Gomendio 1991 Sperm shape and size: evolutionary processes in mammals. In "Comparative spermatology 20 years after". ed by Baccetti, B, Serono Symposia Publication from Raven Press, Vol. 75 pp 1001-1010

Yanagimachi, R., Y. D., Noda, 1970 Fine structure of the hamster sperm head. Am. J. Anat. 128(3): 367-388 